\title{
Assessing the Role of Institutions in Limiting the Environmental Externalities of Economic Growth
}

\author{
Stéphane Dees ${ }^{1}$
}

June 2020, WP \#768

\begin{abstract}
Emissions of pollutants tend to be procyclical as they generally increase with economic growth. However, as government policy has a role to play in the mitigation of the environmental consequences of economic activity, the quality of institutions may influence the procyclicality of pollution and reduce the environmental cost of economic growth. Based on the assumption that changes in emissions are stronger at earlier stages of development, we develop a non-linear framework and confirm first the presence of income-related threshold effects in the relationship between pollution (CO2 and greenhouse gas emissions) and growth, for a panel of 142 countries over a period spanning from 1960 to 2017 . We also find that institutional quality influences this relationship, lowering both the value of the threshold and the degree of procyclicality of emissions. These results bring therefore evidence that higher institutional quality can attenuate the environmental externalities of economic growth.
\end{abstract}

Keywords: CO2 Emissions, GHG Emissions, Economic Growth, Institutions JEL classification: C33, O44, Q56, Q58

\footnotetext{
${ }^{1}$ Banque de France et Univ. Bordeaux, stephane.dees@banque-france.fr 


\section{NON-TECHNICAL SUMMARY}

Emissions of pollutants tend to be procyclical as they generally increase with economic growth. At the same time, the intensity emissions along the development path is not linear, as it is relatively higher for medium-income countries compared to both low-income and high-income countries, giving rise to a possible inverted U-curve in the relationship between economic development and environmental degradation.

Government policy has a role to play in mitigating the environmental consequences of growth. First, a good environmental policy could advance the turning point and lower the size of the maximum emissions when reaching this threshold development level. Second, active environmental policies are justified even at early stages of development, given that the accumulation of environmental damages may be far greater than the present value of higher future income. Third, while environmental degradation depends on higher growth at early stages of development, the extent of the procyclicality of emissions largely depends on the efficiency of markets and policies. Against this background, the quality of institutions may influence the procyclicality of pollution and reduce the environmental externalities of economic growth.

This empirical study focuses on the procyclicality of emissions and the role of institutions in moderating them. The originality of the work is threefold. First, it is based on an up-to-date database including a very large number of countries over a long period (142 countries over 1960-2017), allowing to account for the heterogeneity in levels and speeds of economic development as well as different qualities in institutional settings. Second, it provides an empirical evidence on the role of institutions in moderating the environmental externalities of economic growth, supporting recent theoretical work on the need for governments to design environmental policy that responds to business cycle conditions. Third, the empirical approach is designed to tackle all critical issues usually encountered when testing empirically the pollution-income nexus by adopting a non-linear empirical approach while accounting for the various criticisms made to previous empirical work. More specifically, the approach is immune to issues related to the integration order of variables and accounts for endogeneity issues, bi-directional causality, heterogeneity across countries and cross-sectional dependence.

The empirical results first confirm the presence of threshold effects in the relationship between pollution and growth. In the case of $\mathrm{CO} 2$ emissions, we find an inflexion point in the average growth of emissions for countries whose per capita income is greater than U.S.\$ 18,500. Our results also confirm a significant degree of procyclicality of emissions. For one percentage point increase in real per capita GDP growth, the emissions of CO2 are higher by 0.5 percentage point. We then test for the role of institutional quality in the relationship between pollution and growth. Our empirical analysis shows that countries with better institutional quality experience inflexion or turning points at lower per capita income. Moreover, once such threshold development levels are passed, CO2 emission growth is much lower for countries with high-quality institutions. The procyclicality of emissions is also reduced for countries with the best institutional scores. By reducing the procyclicality of pollution, the improvement in institutional quality is therefore a key factor in attenuating the environmental externalities of economic growth. 


\title{
Per capita CO2 emissions and per capita GDP (USD)
}

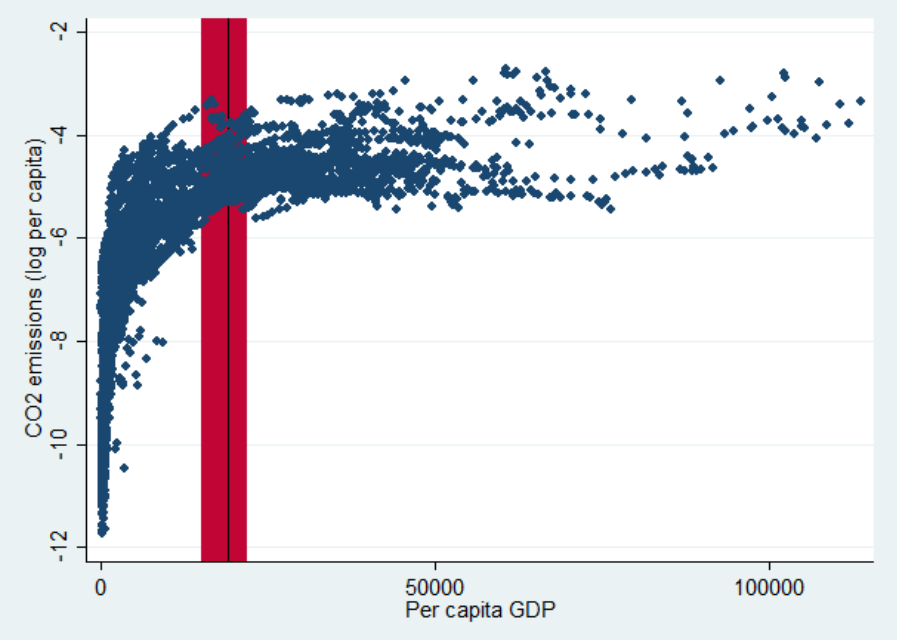

Note: the figure shows the relationship between (per capita) CO2 emissions (in log) and (per capita) income.The black vertical line corresponds to the average value of the threshold estimates. The red area corresponds to the range of threshold estimates.

Sources: World Bank, Authors' calculations.

\section{Évaluer le rôle des institutions dans l'atténuation des externalités environnementales de la croissance économique}

\begin{abstract}
RÉSUMÉ
Les émissions de polluants ont tendance à être procycliques car elles augmentent généralement avec la croissance économique. Cependant, comme les politiques publiques jouent un rôle dans l'atténuation des conséquences environnementales de l'activité économique, la qualité des institutions peut influencer la procyclicité de la pollution et réduire le coût environnemental de la croissance. En partant de l'hypothèse que les variations des émissions sont plus fortes aux premiers stades de développement, nous élaborons un cadre non linéaire et confirmons d'abord la présence d'effets de seuil liés aux niveaux de revenu dans la relation entre pollution (émissions de $\mathrm{CO} 2$ et de gaz à effet de serre) et croissance, pour un panel de 142 pays sur une période allant de 1960 à 2017. Nous constatons également que la qualité des institutions influence cette relation, abaissant à la fois la valeur du seuil et le degré de procyclicité des émissions. Ces résultats montrent donc qu'une meilleure qualité des institutions peut atténuer les externalités environnementales de la croissance économique.
\end{abstract}

Mots-clés : émissions de CO2, émissions de gaz à effet de serre, croissance économique, institutions

Les Documents de travail reflètent les idées personnelles de leurs auteurs et n'expriment pas nécessairement la position de la Banque de France. Ils sont disponibles sur publications.banque-france.fr 


\section{Introduction}

The deterioration of the environment as a side effect of economic growth has become the subject of an abundant literature, which tries to explain two stylised facts. First, emissions of pollutants tend to be procyclical as they generally increase with economic growth. A simple contemporaneous correlation analysis based on a sample of 142 countries at various stage of developments over the period 1960-2017 shows indeed such a procyclicality. As shown by Table 1, the correlation between changes in per capita emissions and per capita GDP is positive in $90 \%$ of the cases for CO2 emissions (3/4 for greenhouse gas or GHG emissions). Although the distribution of this correlation varies across countries, this stylised fact is widespread over the sample with the median correlation at $33 \%$ in the case of $\mathrm{CO} 2$ emissions and $22 \%$ in the case of GHG emissions. Even the first quartile of the distribution shows non-negative comovements and the third quartile points to correlations around $50 \%$ in both cases.

A second well-known stylised fact relates to the intensity emissions along the development path. While on average per capita emission of CO2 has grown by $2.3 \%$ per year over 1960-2017 (0.3\% for GHG emissions), it is relatively higher for medium-income countries compared to both low-income and high-income countries, giving rise to a possible inverted U-curve in the relationship between economic development and environmental degradation. Based on the seminal work by Shafik and Bandyopadhyay (1992), Panayotou (1993), Grossman and Krueger (1991) and Selden and Daqing (1994), the hypothesis that the pollution-income nexus follows an inverted U-curve, also known as the Environmental Kuznets Curve (thereafter EKC), predicts that starting from low income levels, emissions would increase with economic development but at a lower speed and up to a certain level of income - the so-called "turning point" - , from which emissions would start to decline (or at least moderate) as per capital GDP further increases. The rationale behind such a non-linearity is that for countries moving from the early stages of economic development, emissions are increasing with the intensification of agriculture and resource extraction together with the expansion of the industrialization process. However, with further economic development, structural changes that introduce energy efficient technologies and expand information-based industries and services, as well as increasing concerns for environmental quality with higher per capital income, result in reduced environmental degradation.

Government policy can also play an important role in mitigating the environmental consequences of growth and therefore influence these two stylised facts. The literature 
Table 1: Some stylised facts on changes in emissions and correlations with economic growth

\begin{tabular}{|l|c|c|}
\hline & CO2 emissions & GHG emissions \\
\hline Correlations between annual changes in per capita emissions and annual per capital GDP growth \\
\hline corr(emission growth, economic growth) 1st quartile & 0.13 & 0.00 \\
corr(emission growth, economic growth) median & 0.33 & 0.22 \\
corr(emission growth, economic growth) 3rd quartile & 0.49 & 0.45 \\
share of positive correlations & 0.89 & 0.74 \\
\hline \multicolumn{2}{|c|}{ Annual changes in per capita emissions by type of countries (in percent) } \\
\hline average emissions - whole sample & 2.3 & 0.3 \\
average emissions - low-income countries & 2.1 & -0.3 \\
average emissions - medium-income countries & 2.8 & 0.8 \\
average emissions - high-income countries & 0.8 & 0.0 \\
\hline
\end{tabular}

Notes: Statistics derived from an unbalanced panel for 142 countries over 1960-2017. See infra for information about sources. Country types by the Department of Economics and Social Affairs of the United Nations, based on per capita GNI in 2012.

shows that government policy can affect the pollution-economic growth nexus through three channels (Panayotou, 2003). First, a good environmental policy could advance the turning point and lower the size of the maximum emissions when reaching this threshold development level. Economic development does not bring per se the decline in environmental degradation, as it is mostly related to the supply and policy reactions to the growing demand for environmental quality. Second, active environmental policies are justified even at early stages of development, given that the accumulation of environmental damages may be far greater than the present value of higher future income. Third, while environmental degradation depends on higher growth at early stages of development, the extent of the procyclicality of emissions largely depends on the efficiency of markets and policies. Thus, the quality of institutions may significantly reduce the environmental externalities of economic growth.

Existing empirical evidence generally focuses on the pollution-income relationship (i.e. testing the EKC in levels) and very few studies pay attention to the procyclicality of emissions (i.e. studying the pollution-income relationship in first differences). Applications are available to single countries, regions, as well as panels of developing and developed countries (see e.g. Kaika and Zervas, 2013a, for a comprehensive survey). Overall, many authors find some empirical support to the EKC, although the evidence does not seem 
robust across country samples or time periods. Moreover, the empirical analysis of the EKC has been criticized owing to several econometric shortcomings (Lieb, 2003 or Kaika and Zervas, 2013b), such as the lack of cointegration among the variables of interest when taken in levels, omitted variable problems, endogeneity of explanatory variables and cross-sectionally correlated error terms. All these issues invalidate the inference if not properly treated.

This article takes a different empirical approach and focuses on the procyclicality of emissions and the role of institutions in moderating them. Our empirical framework relates to the EKC literature only to the extent that we use the non-linearity hypothesis between pollution and income to model the relationship between economic growth and changes in emissions. Although we pay more attention to the dynamics of emissions with respect to economic conditions rather than focusing exclusively on the EKC in levels, our approach also allows us to estimate the levels of per capita income that acts as turning points in the relationship between pollution and development. The originality of our work is threefold. First, we use an up-to-date database including a very large number of countries over a long period of time (142 countries over 1960-2017). Such a database allows us to account for the heterogeneity in levels and speeds of economic development as well as different qualities in institutional settings. Second, we provide an empirical evidence on the role of institutions in moderating the environmental externalities of economic growth. This supports recent theoretical work on the need for governments to design environmental policy that responds to business cycle conditions (e.g. Heutel, 2012 or Annicchiarico and Di Dio, 2015). Third, our empirical approach is designed to tackle all critical issues usually encountered when testing empirically the pollution-income nexus. In particular, we take explicitly account of cross-country heterogeneity in our modelling approach, consider the two-way relationship between emissions and growth and allow for the possibility of cross-sectional error dependencies.

Our empirical results first confirm the presence of threshold effects in the relationship between pollution (CO2 and GHG emissions) and growth, the threshold value depending on the level of countries' GDP per capita. We also find that the institutional quality influences the relationship, as institutions of higher quality reduces the value of the threshold. Moreover, for a given level of economic growth, the countries with better institutions are also found to pollute less. Altogether, this results bring therefore evidence that higher institutional quality can attenuate the environmental degradation of economic growth, as policy responds more effectively to the environmental externalities of economic growth.

Section 2 presents the specification chosen to estimate the relationship between pol- 
lution and growth, showing how our empirical approach circumvents the usual criticisms made to existing empirical analyses. Section 3 presents our empirical results, including estimations of the pollution-economic growth nexus as well as the role of the quality of institutions in reducing the procyclicality of emissions. Section 4 concludes.

\section{Specifying the relationship between pollution and growth: a non-linear approach}

\subsection{Criticisms made to existing empirical analyses of the pollution- income nexus}

Many econometric issues have been identified in the existing empirical literature on the relationship between economic growth and pollution (see e.g. Kaika and Zervas, 2013b, or Haseeb et al., 2018). These issues have been regularly put forward to criticize the foundation of the EKC hypothesis (see e.g. Stern, 2004). We can categorize them into three main groups: (i) issues related to the integration order of variables; (ii) endogeneity issues and bi-directional causality; and (iii) cross-sectional dependence.

First, many early empirical studies on the EKC tend to mix stationary $(\mathrm{I}(0))$ and nonstationary $(\mathrm{I}(1))$ variables. More recent papers carry out unit root and cointegration tests in order to find long-term relationships between emissions and its potentially explanatory variables. For instance, Lee and Lee (2009) show that the series of real GDP and CO2 emissions are a mixture of stationary and non-stationary series. They also find that panel unit root tests can lead to misleading inferences. Thus, cointegration analysis may be an inappropriate method.

Second, most of the empirical literature on the EKC assumes that causality runs from income to environmental degradation. In other words, income growth should be exogenous to environmental quality. However, Arrow et al. (1995) for instance argue that the causality should be considered as bi-directional, as pollution affects in turn the process of economic growth. Some studies consider the analysis of the EKC through the inclusion of potential reverse causality from environmental degradation and income growth. In fact, the results are quite mixed and the direction of causality, which is not unique, varies across countries and regions (see the survey by Kaika and Zervas, 2013b). This heterogeneity is another related issue that is usually neglected in the empirical studies of the EKC (see e.g. Haseeb et al., 2018) and that should be properly taken into 
consideration in any empirical work.

Third, most of the empirical evidence on the EKC relies on panels that do not allow for error cross-sectional dependence. In other words, it is generally assumed that errors are independently distributed. However, it is generally found that the errors of panel regression of the EKC are cross-sectionally correlated (Apergis, 2016). Ignoring this leads to incorrect inference and in some cases inconsistent estimates, depending on the nature of the cross-section dependence (Phillips and Sul, 2003, or Chudik et al., 2016). To our knowledge, only Apergis (2016) uses approaches that account for cross-sectionally dependence of errors in the context of the EKC. However, his study relies on a limited number of countries (15 OECD countries) and neglects the issue of the procyclicality of emissions. Moreover, the estimates may suffer from omitted variable bias, as no control variable is used in the equations.

\subsection{Empirical framework}

Our empirical approach focuses on the procyclicality of emissions and follows the EKChypothesis only to the extent that it introduces a non-linear relationship between economic growth and the quantity of pollutants emitted according to the level of income. Such a non-linearity is related to the possible existence of a threshold effect in the pollution-income relationship depending on economic development level (measured by per capita GDP), beyond which environmental degradation drops off significantly.

Our methodological approach accounts for all the aforementioned shortcomings. First, our approach focuses on the procyclicality of emissions, i.e. how the changes in emissions is affected by economic growth. All variables are stationary, thus circumventing the cointegration analysis issue. Second, we pay attention to the bi-directional relationship between pollution and growth. Third, our approach allows for cross-section dependence of the error terms.

We adopt here an approach proposed by Chudik et al. (2017), which was initially applied to the existence of threshold effects in the relationships between economic growth and the level of public debt. In our case, the hypothesis of interest is that the change in emission of pollutants becomes negative - or at least decreases - once per capita GDP exceeds a certain threshold, noted $\tau$.

Noting $I(A)$, an indicator variable that takes the value of unity if event A occurs and 0 otherwise, we can formalize this hypothesis as follows: 


$$
\Delta p_{i t}=a_{1} I\left[y_{i t} \leq \tau\right]+a_{2} I\left[y_{i t}>\tau\right]+e_{i t}
$$

where $p_{i t}$ is an indicator of (per capita) pollution in country $i$ at year $t$ in logarithmic form (i.e. per capita pollutant emission), $\Delta p_{i t}$ being thus the annual growth rate of emissions, $y_{i t}$ is the log-level of (per capita) income and $e_{i t}$ is the error term.

Eq. (2.1) can be written equivalently as:

$$
\Delta p_{i t}=\gamma+\delta I\left[y_{i t}>\tau\right]+e_{i t}
$$

where $\gamma=a_{1}$ and $\delta=a_{2}-a_{1}$.

Pooled estimates of Eq. (2.2) yields two central pieces of information included in Eq. (2.1). We can indeed note first that $\hat{\gamma}=\hat{a}_{1}$ gives the average growth rate of pollutant emission when income is less than or equal to the threshold $\left(y_{i t} \leq \tau\right)$. Second, $\hat{\delta}=\hat{a}_{2}-\hat{a}_{1}$ gives the difference between the average growth of pollutant emission when income exceeds the threshold $\left(y_{i t}>\tau\right)$ and the average emission growth when income does not exceed this threshold $\left(y_{i t} \leq \tau\right)$.

Assuming that there is a positive relationship between environmental degradation and income at the early stages of development $(\gamma>0)$, two types of non-linearity corresponding to the EKC can be found with this specification:

- $\delta<0$ and $|\delta|>\gamma$, the EKC hypothesis is verified in its inverted U-form. After an increase in emission up to an income level threshold (the so-called "turning point"), emissions decline with further increases in income.

- $\delta<0$ and $|\delta| \leq \gamma$, the EKC hypothesis is verified only in the sense that there is an inflexion point in the pollution-income relationship corresponding to a level of income beyond which the rate of growth of emissions is lower (but not negative) than the one observed at lower economic development levels.

The existence of threshold effects on emission growth can therefore be verified in this framework by testing the null hypothesis that $H_{0}: \delta=0$ against the one-sided alternative $H_{1}: \delta<0$.

Equation 2.2 only introduces non-linearity in the pollution-income relationship. To model the procyclicality of emissions, we need to extend it by introducing economic growth as follows:

$$
\Delta p_{i t}=\gamma_{i, p}+\delta I\left[y_{i t}>\tau\right]+\mu \Delta p_{i, t-1}+\nu \Delta y_{i, t-1}+e_{i t}
$$


for $i=1,2, \ldots, N$ and $t=1,2, \ldots, T$.

To treat the issue of endogeneity of growth to changes in emissions, we combine equation 2.3 with an equation for $y_{i t}$,

$$
\Delta y_{i t}=\gamma_{i, y}+\kappa \Delta y_{i, t-1}+\xi \Delta p_{i, t-1}+\epsilon_{i t}
$$

allowing therefore feedback effects from lagged pollution to current output growth, $y_{i t}$. If we estimated $\delta$ with equation 2.3 only, our estimate would be biased as $e_{i t}$ is likely to be correlated with $\epsilon_{i t}$. Chudik et al. (2017) show that this bias can be substantial and suggest to model the correlation between the two innovations in order to deal with such a simultaneity bias. However, we can derive a reduced-form equation to identify the threshold effect in the pollution equation by assuming a linear dependence between the innovations, written as:

$$
e_{i t}=\eta_{i} \epsilon_{i t}+u_{i t}
$$

where $u_{i t}=e_{i t}-E\left(e_{i t} \mid \epsilon_{i t}\right)$ and $u_{i t}$ uncorrelated with $\epsilon_{i t}$ by construction.

If we substitute equation 2.5 in equation 2.3 and then substitute equation 2.4 for $\epsilon_{i t}$, we obtain the following reduced-form panel threshold-Autoregressive Distributed Lag (ARDL) specification for $\Delta p_{i t}$.

$$
\Delta p_{i t}=a_{i}+\delta I\left[y_{i t}>\tau\right]+\rho_{i} \Delta p_{i, t-1}+b_{i 0} \Delta y_{i t}+b_{i 1} \Delta y_{i, t-1}+u_{i t}
$$

where $a_{i}=\gamma_{i, p}-\eta_{i} \gamma_{i, y}, \rho_{i}=\mu-\eta_{i} \xi, b_{i 0}=\eta_{i}, b_{i 1}=\nu-\eta_{i} \kappa$. Since $u_{i t}$ is uncorrelated with $\epsilon_{i t}$, then conditional on $\left(\Delta p_{i, t-1}, \Delta y_{i t}, \Delta y_{i, t-1}\right), u_{i t}$ and $y_{i t}$ will also be uncorrelated, which implies that $u_{i t}$ and $I\left[y_{i t}>\tau\right]$ will be uncorrelated. As a result, for a given value of $\tau, \lambda$ can be consistently estimated by pooled least squares techniques of equation 2.6 . The coefficient $\tau$ can be retrieved by a grid search procedure. Although $\delta$ is assumed to be homogenous across countries (as in the EKC literature), we do not need to impose any homogeneity restrictions on the other parameters. Therefore, the estimation of equation 2.6 deals with simultaneity bias while allowing for slope heterogeneity in the relationship between pollution and growth. As the assumption of homogeneity of $\tau$ and $\delta$ across countries may be strong, we will also consider the possibility of heterogeneity in these parameters. For this purpose, we will first allow $\delta$ to be country-specific and second, we will investigate their possible heterogeneity according to the quality of institutions of our sample countries. 
Moreover, our approach allows us to investigate the long-run effects of economic growth on pollution. Pesaran and Smith (1995) and Pesaran (1997) show that the ARDL approach can be used for long-run analysis and that the ARDL methodology is valid regardless of whether the regressors are exogenous or endogenous and regardless of whether the underlying variables are $\mathrm{I}(0)$ or $\mathrm{I}(1)$. These features of the panel ARDL approach are therefore appropriate for relationship between economic growth and pollution, as reverse causality could be very important in our empirical application.

The ARDL approach is also appropriate to deal with cross-section dependence of the residuals. Following Chudik and Pesaran (2015), we will augment our ARDL specifications with cross-section averages of the dependent and explanatory variables in so-called Cross-Section-ARDL models (CS-ARDL).

Finally, our approach allows us to also include control variables to account for a potential omitted variable bias in the estimation process.

\section{Empirical results}

In this section, we present first our sample and the source of our data before estimating the model and testing for the presence of threshold effects in the procyclical relation of emissions. We will subsequently focus on the role of institutional quality in the determination of the threshold $(\tau)$ and the threshold-effect coefficient $(\delta)$ in order to bring evidence on the role of institutions in attenuating environmental externalities of economic growth.

\subsection{Sample and data source}

Our sample covers 142 countries of various levels of development, including 51 highincome countries ${ }^{1}$ (of which 33 advanced economies according to the IMF classification), 41 upper-middle income countries, 29 lower middle income countries and 20 low income countries. We work with an unbalanced panel that spans over a sample from 1960 to 2017. The dependent variables include CO2 emissions (per capita) and GHG emissions (per capita). Economic growth is measured by the change in real GDP and the treshold effect is determined according to per capita GDP expressed in 2010 U.S. dollar. We also add in our equations various control variables usually found in the literature, including trade openness, energy consumption, the share of manufacture industry in total value

\footnotetext{
${ }^{1}$ Based on the World Bank classification 2017.
} 
added and the share of urban population?2, Table 6 in Appendix describes the variables used in our empirical part as well as the statistical sources. Most of the data come from the World Development Indicators Database of the World Bank. Finally, our institutional quality variables are from the Worldwide Governance Indicators. They reflect both the regulatory and the rule-of-law quality of countries' institutional framework.

\subsection{Determining and testing the presence of threshold effects}

Testing the threshold effects in equation 2.6 is equivalent of testing $\delta=0$. Following Chudik et al. (2017), we rewrite this equation compactly for $t=1,2, \ldots, T$ using vector notations as follows:

$$
\Delta \mathbf{p}_{i}=\mathbf{Q}_{i} \boldsymbol{\theta}_{i}+\boldsymbol{\delta}^{\prime} \mathbf{H}_{i}(\tau)+\mathbf{u}_{i}, \text { for } \mathrm{i}=1,2, \ldots, N
$$

where $\Delta \mathbf{p}_{i}$ is a $T \times 1$ vector of observations on $\Delta p_{i t}, \mathbf{Q}_{i}$ is a $T \times h$ observation matrix of regressors $\mathbf{q}_{i}=\left(1, \Delta p_{i, t-1}, \Delta y_{i t}, \Delta p_{i t-1} \text {, controls }\right)^{\prime}$, and $\mathbf{H}_{i}(\tau)$ is a $T \times 1$ matrix of observations on the threshold variable $\mathbf{h}\left(y_{i t}, \tau\right)=I\left[y_{i t}>\tau\right]$. The filtered pooled estimator of $\boldsymbol{\delta}$ for a given value of the threshold $\tau$ is given by

$$
\hat{\boldsymbol{\delta}}(\tau)=\left[\sum_{i=1}^{N} \mathbf{H}_{i}^{\prime}(\tau) \mathbf{M}_{i} \mathbf{H}_{i}^{\prime}(\tau)\right]^{-1} \sum_{i=1}^{N} \mathbf{H}_{i}^{\prime}(\tau) \mathbf{M}_{i} \Delta \mathbf{p}_{i}
$$

where $\mathbf{M}_{i}=\mathbf{I}_{T}-\mathbf{Q}_{i}\left(\mathbf{Q}_{i}^{\prime} \mathbf{Q}_{i}\right)^{-1} \mathbf{Q}_{i}$ and the regressors in $\mathbf{Q}_{i}$ are the filtering variables.

For testing the null hypothesis $\delta=0$, we use the SupT test statistics (see Andrews and Ploberger, 1994, or Chudik et al., 2017), which is given by:

$$
\operatorname{SupT}=\sup _{\tau \in \Xi}\left[\sqrt{T_{N T}(\tau)}\right]
$$

where $\Xi$ represents the admissible set of values for $\tau$ and

$$
T_{N T}(\tau)=\frac{\left(R S S_{r}-R S S_{u}\right)}{R S S_{u} /(n-s)}
$$

where $R S S_{u}$ is the residual sum of squares of the unrestricted model 3.1 , $R S S_{r}$ is the residual sum of squares of the restricted model under the null $\delta=0, n$ is the number of observations $(n=N T)$, and $s$ is the total number of estimated coefficients in the

\footnotetext{
${ }^{2}$ Owing to the large number of parameters to be estimated, these control variables are added one at a time as robustness checks of our main results, which include energy consumption only.
} 
unrestricted model $(s=N h+r)$.

As mentioned above, we also need to deal with possible correlation across the errors $u_{i t}$. Such error cross-sectional dependencies could be due to regional or world-wide effects of local pollution as well as omitted common factors. Apergis (2016) gives some evidence of the presence of cross-sectionally correlated errors in panels relating pollution and income. We deal with this issue by assuming that the errors in equation 2.6 have a multi-factor error structure as follows:

$$
u_{i t}=\omega_{i}^{\prime} \mathbf{f}_{t}+v_{i t}
$$

where $\mathbf{f}_{t}$ is the $m \times 1$ vector of unobserved common factors, $\omega^{\prime}{ }_{i}$ the $m \times 1$ vector of factor loadings and $v_{i t}$ the idiosyncratic errors. We approximate the factor space following the method developed by Chudik and Pesaran (2015) in the context of dynamic heterogeneous panels. This approach deals with the presence of unobserved common factors by augmenting $\mathbf{Q}_{i}$ with cross-section averages of the regressors, the dependent variables, and their lags.

Therefore, our empirical exercise will rely on two panel-threshold models:

- ARDL models, i.e. a generalization of equation 2.6 with $p$ lags:

$$
\Delta p_{i t}=a_{i}+\delta I\left[y_{i t}>\tau\right]+\sum_{l=1}^{p} \rho_{i l} \Delta p_{i, t-l}+\sum_{l=0}^{p} b_{i l} \Delta y_{i, t-l}+u_{i t}
$$

- CS-ARDL models that allow for error cross-sectional dependence by including crosssection averages of the regressors, the dependent variables and their lags:

$$
\Delta p_{i t}=a_{i}+\delta I\left[y_{i t}>\tau\right]+\sum_{l=1}^{p} \rho_{i l} \Delta p_{i, t-l}+\sum_{l=0}^{p} b_{i l} \Delta y_{i, t-l}+\sum_{l=0}^{p} c_{i l, h} \overline{\mathbf{h}}_{t-l}+u_{i t}
$$

where $\overline{\mathbf{h}}_{t}=\left(\overline{\Delta p}_{t}, \overline{\Delta y}_{t}\right)^{\prime}, \overline{\Delta p}_{t}$ and $\overline{\Delta y}_{t}$ are the cross-country averages of emissions and income growth.

To account for possible heterogeneity across countries regarding the value of $\delta$, we also estimate equations 3.6 and 3.7 with country-specific $\delta_{i}$.

The threshold values $\tau$ are determined through a grid search procedure over values for GDP per capita (with incrementing steps of U.S.\$500) using the value of SupT 
together with the sign and significance of $\delta$ as criteria. As our main objective is not only to test the presence of threshold effects but also to estimate the long-run effects of a persistent increase in economic growth on emissions. We also derive from our models the long-run coefficients of growth on pollution by following the approach by Chudik et al. (2016). Noting $\overline{\mathbf{b}}_{i}$, the long-run coefficient of growth on pollution, we can derive it from the following formula (which applies both to ARDL and CS-ARDL specifications):

$$
\overline{\mathbf{b}}_{i}=\frac{\sum_{l=0}^{p} b_{i l}}{1-\sum_{l=1}^{p} \rho_{i l}}
$$

The mean long-run effects $\overline{\mathbf{b}}$ are estimated as $N^{-1} \sum_{i=1}^{N} \overline{\mathbf{b}}_{i}$ and the inference is based on the usual non-parametric estimator of asymptotic variance of the mean group estimator (Chudik et al., 2016).

Table 2 presents the estimated threshold values $\hat{\tau}$ found for $\mathrm{CO} 2$ emissions, together with the corresponding SupT test statistics, the estimates of the threshold effect, $\hat{\delta}$, the long-run effects of growth, $\overline{\mathbf{b}}$, and the CD test statistics of Pesaran (2004) for detecting the presence of cross-section dependence of the errors. The first column of each estimation presents the case with common $\delta$, while the second one refers to the specifications with country-specific $\delta_{i}$ (the value of $\hat{\delta}$ reported in the table corresponds to the pooled mean group estimate of $\delta_{i}$ ). Table 3 reports the same information for GHG emissions.

Table 2: Estimations and tests of income-threshold effects on pollution - CO2 emissions

\begin{tabular}{|c|c|c|c|c|c|c|c|c|}
\hline & \multicolumn{2}{|c|}{$\operatorname{ARD}(1,1)$} & \multicolumn{2}{|c|}{$\operatorname{ARDL}(2,2)$} & \multicolumn{2}{c|}{ CS-ARDL $(1,1,1)$} & \multicolumn{2}{c|}{ CS-ARDL $(2,2,2)$} \\
\hline & $\delta$ & $\delta_{i}$ & $\delta$ & $\delta_{i}$ & $\delta$ & $\delta_{i}$ & $\delta$ & $\delta_{i}$ \\
\hline$\hat{\tau}$ & 18.0 & 18.5 & 18.5 & 17.0 & 18.5 & 20.0 & 18.5 & 19.5 \\
$S u p T$ & $21.33^{* * *}$ & $20.14^{* * *}$ & $18.00^{* * *}$ & $15.33^{* * *}$ & $18.96^{* * *}$ & $17.67^{* * *}$ & $14.53^{* * *}$ & $13.78^{* * *}$ \\
$\hat{\delta}$ & $-0.013^{*}$ & $-0.013^{* *}$ & -0.008 & $-0.035^{*}$ & $-0.012^{*}$ & $-0.013^{*}$ & $-0.014^{*}$ & $-0.011^{*}$ \\
$\overline{\mathbf{b}}$ & $0.48^{* * *}$ & $0.48^{* * *}$ & $0.54^{* * *}$ & $0.49^{* * *}$ & $0.58^{* * *}$ & $0.50^{* * *}$ & $0.49^{* * *}$ & $0.61^{* * *}$ \\
\hline $\mathrm{CD}(\mathrm{p}$-value) & 0.10 & 0.07 & 0.24 & 0.17 & 0.05 & 0.05 & 0.06 & 0.09 \\
$R^{2}$ & 0.26 & 0.26 & 0.33 & 0.34 & 0.27 & 0.27 & 0.36 & 0.37 \\
$N \times T$ & 4092 & 4092 & 4034 & 4034 & 3983 & 3983 & 3786 & 3786 \\
\hline
\end{tabular}

Notes: Statistical significance denoted by $* 10 \%, * * 5 \%$, and $* * * 1 \%$. CD (p-value) is the p-value of the cross-section dependence test statistic of Pesaran (2004).

The results for $\mathrm{CO} 2$ emissions confirm the existence of a threshold effect (i.e. a non- 
linearity in the relation between the growth of emissions and per capita income) at a level ranging from U.S.\$17,000 to 20,000 per capita (with U.S.\$18,500 being the most frequent value). This effect is supported by the SupT test statistics. The ARDL and CS-ARDL models yield a negative estimate of this effect $(\hat{\delta})$, which is significant in 5 over 8 cases, validating the very presence of the EKC (i.e. from $\hat{\tau}>$ U.S. $\$ 18,500$ further growth lead to lower changes in emissions). As noted above, the ARDL models do not allow for error cross-sectional dependence and can yield incorrect inference regarding the presence of threshold effects. Indeed, the CD test of Pesaran (2004) points to the presence of cross-sectional dependence of the errors. The CS-ARDL models, which deal with this issue, also find evidence of threshold effects and a negative effect of income on pollution for higher income levels. The CD tests are in this case not significant, meaning that the error cross-sectional dependence has disappeared with such a modelling approach.

The parameter $\hat{\delta}$, which captures the extent of the negative effect on pollution for higher income levels, is negative, with a value around -0.013 . This means that once a country has reached the threshold in terms of per capita income, the yearly growth of $\mathrm{CO} 2$ emissions is 1.3 percentage point lower. As the average CO2 emission growth is $3.6 \%$ per annum for countries whose income is below the threshold, our results mean that the threshold is not a turning point but an inflexion point, as the emission growth for higher income countries remains positive at $2.3 \%(0.036-0.013)$.

The value of the long-run elasticity of pollution to economic growth $(\overline{\mathbf{b}})$ is around 0.5 , meaning that for each percentage point increase in real output growth, CO2 emissions are higher by 0.5 percentage point on average. The specifications also include the consumption of electricity as control variable, which appear with positive, significant effects on CO2 emissions. The other control variables (openness, the share of industry and urbanisation) have also been included as robustness checks but do not change the main result: 3

For total GHG emissions, the results are more or less similar. The threshold value is slightly higher (between U.S.\$18,500 and U.S.\$22,250, with U.S.\$20,000 being the most frequent value) and the extent of the negative effect on pollution for higher income levels is also slightly higher than that found for CO2 emissions. The estimations of ARDL models do not feature the presence of cross-section dependence of the error terms, as shown by the p-values of Pesaran's CD test. However, we maintain the estimations of specification including cross-section averages of the regressors.

The extent of the negative effect on pollution for higher income levels $(\hat{\delta})$ is negative,

\footnotetext{
${ }^{3}$ Results available upon request
} 
Table 3: Estimations and tests of income-threshold effects on pollution - GHG emissions

\begin{tabular}{|c|c|c|c|c|c|c|c|c|}
\hline & \multicolumn{2}{|c|}{$\operatorname{ARDL}(1,1)$} & \multicolumn{2}{|c|}{$\operatorname{ARDL}(2,2)$} & \multicolumn{2}{|c|}{$\operatorname{CS}-\operatorname{ARDL}(1,1,1)$} & \multicolumn{2}{c|}{ CS-ARDL $(2,2,2)$} \\
\hline & $\delta$ & $\delta_{i}$ & $\delta$ & $\delta_{i}$ & $\delta$ & $\delta_{i}$ & $\delta$ & $\delta_{i}$ \\
\hline$\hat{\tau}$ & 20.0 & 22.0 & 20.0 & 20.0 & 18.5 & 20.0 & 22.0 & 20.0 \\
SupT & $30.34^{* * *}$ & $14.09^{* * *}$ & $12.48^{* * *}$ & $11.92^{* * *}$ & $13.57^{* * *}$ & $12.77^{* * *}$ & $13.59^{* * *}$ & $13.07^{* * *}$ \\
$\hat{\delta}$ & $-0.014^{* *}$ & -0.006 & -0.021 & $-0.016^{* * *}$ & $-0.017^{* *}$ & $-0.015^{* * *}$ & $-0.022^{*}$ & $-0.021^{* * *}$ \\
$\overline{\mathbf{b}}$ & $0.32^{* * *}$ & $0.31^{* * *}$ & $0.32^{* *}$ & $0.34^{* *}$ & $0.33^{* * *}$ & $0.34^{* * *}$ & $0.33^{* *}$ & $0.35^{* *}$ \\
\hline $\mathrm{CD}$ & 0.03 & 0.00 & 0.00 & 0.00 & 0.00 & 0.0 .0 & 0.00 & 0.00 \\
$R^{2}$ & 0.12 & 0.26 & 0.34 & 0.35 & 0.27 & 0.27 & 0.37 & 0.37 \\
$N \times T$ & 3552 & 3553 & 3427 & 3427 & 3432 & 3432 & 3108 & 3108 \\
\hline
\end{tabular}

Notes: Statistical significance denoted by ${ }^{*} 10 \%, * * 5 \%$, and $* * * 1 \%$. CD is the cross-section dependence test statistic of Pesaran (2004).

with a value around -0.019 , which means that once a country has reached the threshold in terms of per capita income, the annual growth of GHG emissions is 1.9 percentage point lower. As the average GHG emission growth is $0.3 \%$ per annum for countries whose income is below the threshold, our results imply that, unlike the results for $\mathrm{CO} 2$ emissions, the threshold is this time a turning point, as the emission declines at an average rate of $1.2 \%$ per annum $(0.003-0.019)$ for countries whose per capita income is higher than the threshold value.

The value of the long-run elasticity of pollution to economic growth $(\overline{\mathbf{b}})$ is around $1 / 3$, meaning that for each percentage point increase in real output growth, GHG emissions are higher by 0.3 percentage point on average. As for $\mathrm{CO} 2$ emissions, the results reported also include electricity consumption as control variable, which enters with positive, significant effects on GHG emissions.

We can visualize our results by plotting our pollution-income nexus together with the estimated thresholds. Fig. 1 shows the relationship between (per capita) CO2 emissions (in log) and (per capita) income. This graph shows the positive relationship for low per capita GDP level and seems to moderate for income higher than our estimated thresholds. The same also apply to our second measure of pollution, total (per capita) GHG emissions (Fig. 2). 
Figure 1: Per capita CO2 emissions and per capita GDP (USD)

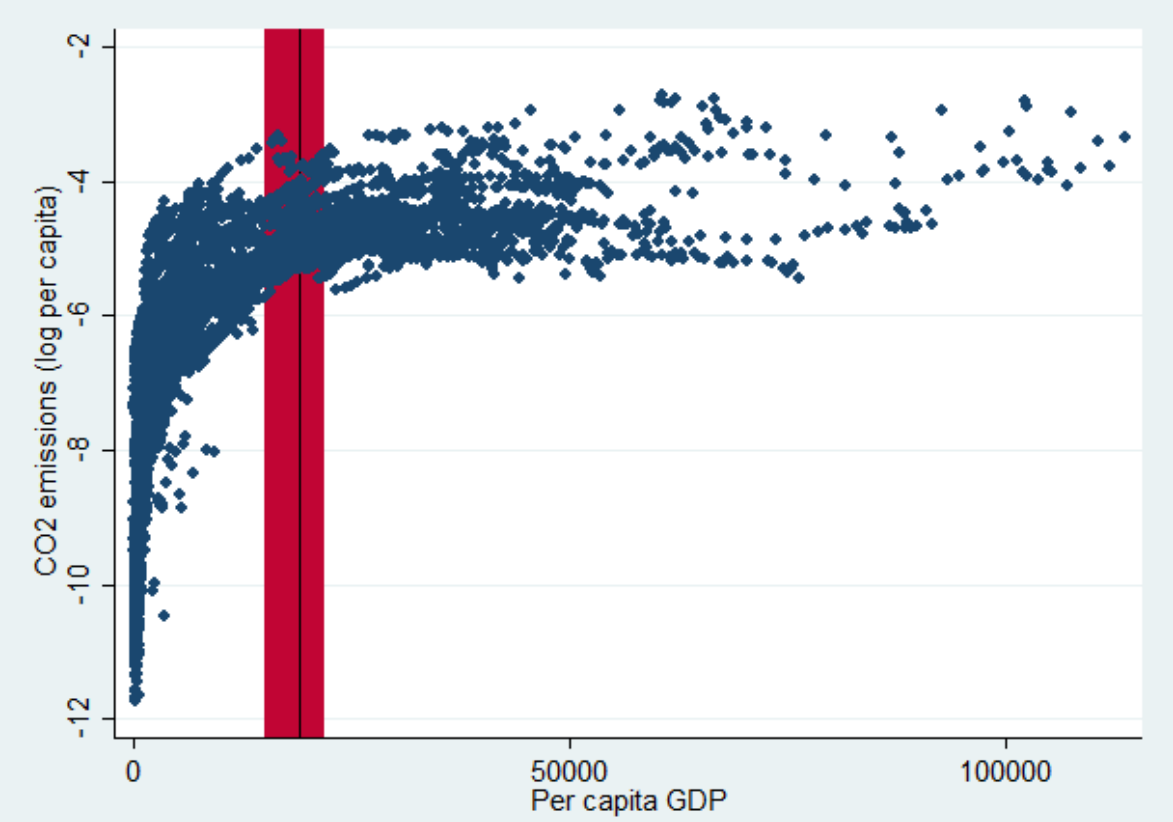

Source: World Bank and author's estimates. The black vertical line corresponds to the average value of the threshold estimates. The red area corresponds to the range of threshold estimates.

Figure 2: Per capita GHG emissions and per capita GDP (USD)

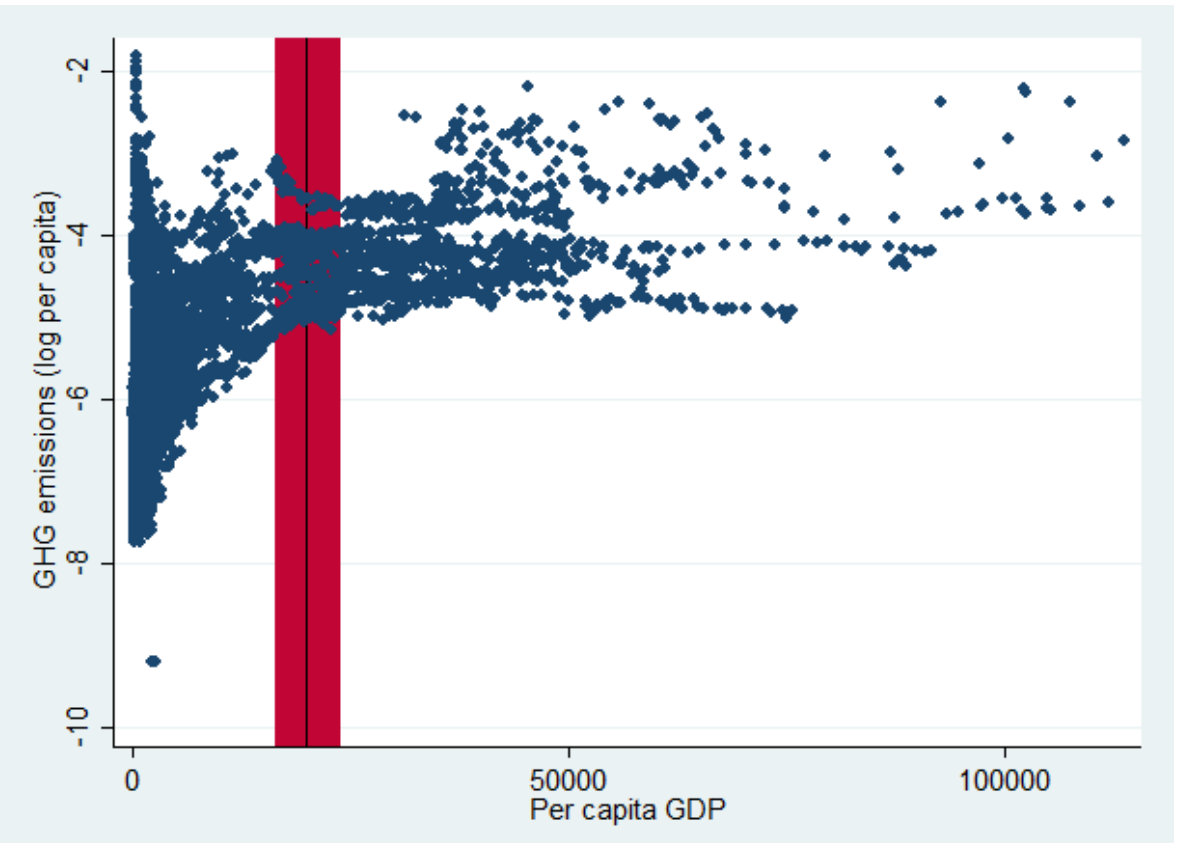

Source: World Bank and author's estimates. The black vertical line corresponds to the average value of the threshold estimates. The red area corresponds to the range of threshold estimates. 


\subsection{The role of institutional quality in the procyclicality of emis- sions}

The literature studying the relationships between institutions and environmental quality is relatively well developed. At the theoretical level, Brock and Taylor (2003) show how institutions influence the income-pollution paths and affect the turning point of the EKC through the influence institutional enforcement has on pollution abatement. The idea is that the ability of environmental policies to reach their objectives depends on the quality of institutions that facilitate the process of policy adoption. Lopez and Mitra (2000) also propose a theoretical contribution that shows that pollution remains much higher for developing countries affected by corruption than the levels reached in developed countries at comparable per capita incomes.

Empirically, many papers deal with the impact of institutions and governance on environmental performance and policy adoption. Based on the 55 papers, Dasgupta and De Cian (2016) conclude their review with three main findings. First, democratic countries and open societies are more likely to support environmental protection. Second, good governance encourages the adoption of environmental policies to improve environmental quality. Third, corruption leads to a sub-optimal use of resources, which results in environmental degradation.

The idea followed here is not only to verify empirically the assumption that the shape of the EKC might be altered by the quality of institutions but also to quantify how good institutions can reduce the procyclicality of emissions. To bring evidence of such effects, we reestimate the previous equations by excluding subsequently from our sample the worst and the best performers in terms of institutional quality. By adjusting our sample in such a way, we will be able to verify how the threshold value $(\tau)$, the average reduction in emission once the threshold has been reached $(\delta)$ and the long-run sensitivity of emissions to economic growth $(\bar{b})$ change according to the quality of institutions ${ }^{4}$.

We use two indicators of institutional quality (both from Worldwide Governance Indicators). The first one refers to the regulatory quality, which gives for each country (and year) a score reflecting perceptions of the ability of governments to "formulate and implement sound policies and regulations that permit and promote private sector devel-

\footnotetext{
${ }^{4}$ Alternatively, we could have used dummy or indicator variables to account for changes in parameter values with different institutional quality levels. However, given that we aim at finding the impact of institutional quality on three different parameters, this approach would have implied a dramatic loss of degrees of freedom and would have therefore altered the quality of the inference.
} 
opment" 5 . As a robustness check ${ }^{6}$, we also use the rule-of-law indicator that "captures perceptions of the extent to which agents have confidence in and abide by the rules of society, and in particular the quality of contract enforcement, property rights, the police, and the courts, as well as the likelihood of crime and violence" 7 .

The use of these indicators allows us to split our sample in percentiles according to the quality of institutions. It is worth noting that the quality of institutions is not necessarily correlated with income level. As shown by Fig. 3, although the highest scores of institutional quality are generally found for high-income countries, our sample with the lowest scores encompasses countries with different income levels. This insures that our institutional quality indicators are not simply proxies of income, which would have otherwise altered our conclusions.

Figure 3: Percentiles of institutional quality indicators and percentiles of per capita GDP

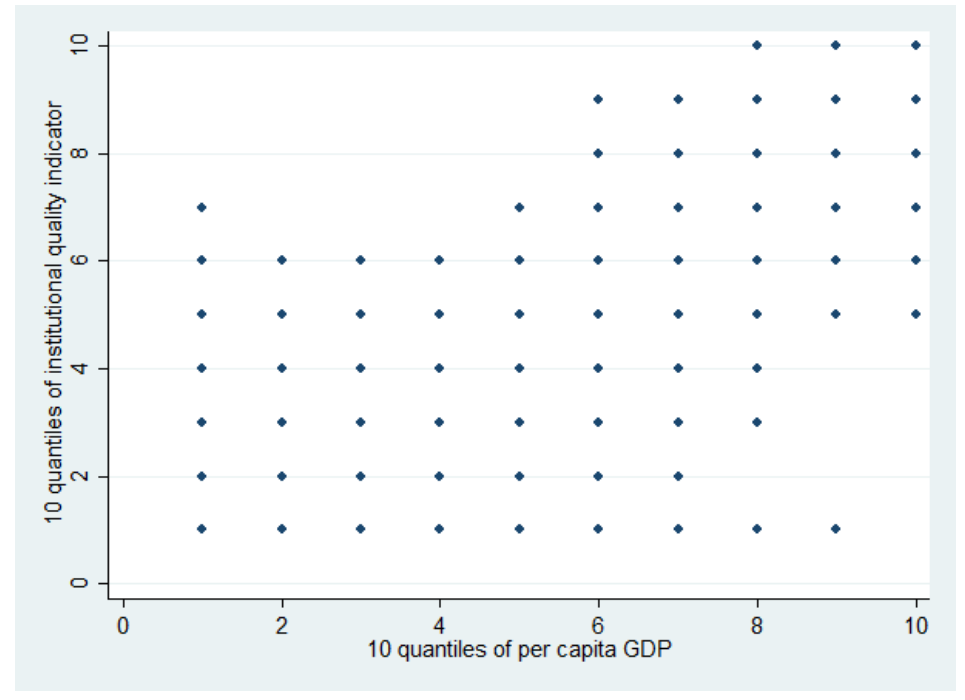

Note: Author's computation

Table 4 presents the results of the sensitivity of our previous estimations for $\mathrm{CO} 2$ emissions to the exclusion of countries according to their institutional quality. We start by excluding the countries with the lowest scores ("worst performers") applying two levels of exclusion: excluding only the first decile and excluding the first two deciles. In other words, we run our estimations for a sample that is applied to countries (sorted our according to their institutional quality), that represents a range from 5 to $100 \%$ of the

\footnotetext{
${ }^{5}$ https://datacatalog.worldbank.org/regulatory-quality-estimate-0

${ }^{6}$ Results are not presented here for the sake of brevity but are available upon request

${ }^{7}$ https://datacatalog.worldbank.org/rule-law-estimate-0
} 
distribution, in the first case, and to 10 to $100 \%$ of the distribution, in the second case. The results confirm the presence of threshold effects but at slightly lower levels than the benchmark ones. The average change in pollution once the threshold has been reached as well as the long-run effect of growth on pollution are also lower. As a result, when excluding the countries with the lowest institutional quality scores (i.e. by increasing the average institutional quality of the sample countries), we find an EKC with a lower threshold value (i.e. the inflexion point in the pollution-income relationships comes with lower income levels) and with a stronger inflexion for countries with higher-than-threshold incomes. More importantly, the degree of procyclicality of emissions is also lower when restriucting our sample to countries with better institutional quality. The comparison of our three parameters of interest with respect to the benchmark case is reported on Fig. 4.

We also perform a similar exercise but by excluding the countries with the highest institutional quality scores ("best performers"). The idea here is to worsen the overall quality of institutions of the remaining sample countries. As shown in Table 4 and in Fig. 4, excluding the countries with the best scores increases the value of the threshold (the inflexion point is reached for higher income levels), deteriorates the average decline in emissions once the threshold has been passed and increases the procyclicality of emissions.

The same exercise is also performed for GHG emissions. Results are reported in Table 5 and the sensitivity of our three key-parameters is graphically represented in Fig. 5 . The results found for $\mathrm{CO} 2$ emissions are confirmed when considering this broader measure of pollution. With higher institutional quality, the turning point comes not only for slightly lower income (U.S.\$ 19,500 instead of U.S.\$20,000) but also with a stronger decline for countries which have passed the threshold (-2.2\% instead of $-1.9 \%)$. Pollution is also less sensitive to economic growth (with an elasticity of 0.31 instead of 0.34). The differences with the benchmark case are even more striking when considering the sample that excludes the countries with the best institutional quality. Therefore, improving the quality of institutions advances the turning point of the EKC and reduces the procyclicality of emissions. Overall, these results confirm that higher institutional quality can attenuate the environmental degradation of economic growth. 
Table 4: Sensitivity of estimations to the exclusion of countries according to institutional quality - CO2 emissions

\begin{tabular}{|c|c|c|c|c|c|c|c|c|}
\hline & \multicolumn{3}{|c|}{ Excl. countries with worst performers } & \multicolumn{2}{c|}{ Excl. countries with best performers } \\
\hline perc. range & \multicolumn{2}{|c|}{$5-100$} & \multicolumn{2}{c|}{$10-100$} & \multicolumn{2}{c|}{$0-90$} & \multicolumn{2}{c|}{$0-95$} \\
\hline & $\delta$ & $\delta_{i}$ & $\delta$ & $\delta_{i}$ & $\delta$ & $\delta_{i}$ & $\delta$ & $\delta_{i}$ \\
\hline$\hat{\tau}$ & 18.5 & 18.5 & 18.5 & 19.0 & 21.5 & 21.5 & 22.0 & 23.5 \\
$S u p T$ & $16.72^{* * *}$ & $15.82^{* * *}$ & $15.73^{* * *}$ & $14.32^{* * *}$ & $14.32^{* * *}$ & $13.09^{* * *}$ & $15.03^{* * *}$ & $14.42^{* * *}$ \\
$\hat{\delta}$ & $-0.018^{* *}$ & $-0.015^{*}$ & $-0.017^{*}$ & $-0.020^{* *}$ & -0.003 & -0.000 & -0.008 & -0.010 \\
$\overline{\mathbf{b}}$ & $0.57^{* * *}$ & $0.53^{* * *}$ & $0.54^{* * *}$ & $0.52^{* * *}$ & $0.67^{* * *}$ & $0.64^{* * *}$ & $0.60^{* * *}$ & $0.59^{* * *}$ \\
\hline $\mathrm{CD}$ & 0.04 & 0.04 & 0.13 & 0.10 & 0.10 & 0.06 & 0.06 & 0.03 \\
$R^{2}$ & 0.37 & 0.38 & 0.41 & 0.42 & 0.38 & 0.38 & 0.37 & 0.38 \\
$N \times T$ & 3638 & 3638 & 3459 & 3459 & 3175 & 3175 & 3457 & 3457 \\
\hline
\end{tabular}

Notes: Statistical significance denoted by $* 10 \%, * * 5 \%$, and ${ }^{* * *} 1 \%$. CD is the cross-section dependence test statistic of Pesaran (2004).

Figure 4: Benchmark estimates and sensitivity to institutional quality - CO2

$\tau$

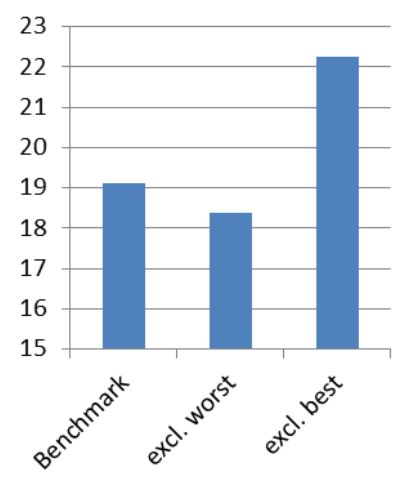

$\delta$

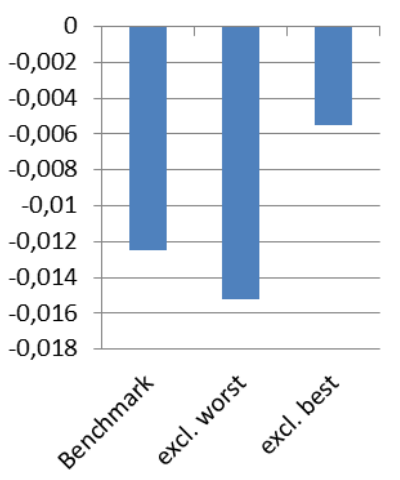

b

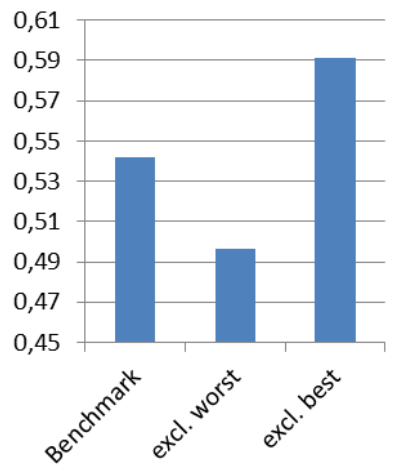

Note: Averages over CS-ARDL models. $\tau, \delta$ and b correspond to the threshold, the rate of change of emissions after the threshold and the long-term effect of GDP growth on emissions. Benchmark corresponds to the average of estimates reported in Table 2 Estimates for "excl. worst" and "excl. best" corresponds to the averages of CS-ARDL(2,2,2) models reported in Table 4 and CS-ARDL $(1,1,1)$ models whose results are available upon request. 
Table 5: Sensitivity of estimations to the exclusion of countries according to institutional quality - GHG emissions

\begin{tabular}{|c|c|c|c|c|c|c|c|c|}
\hline & \multicolumn{3}{|c|}{ Excl. countries with worst performers } & \multicolumn{2}{c|}{ Excl. countries with best performers } \\
\hline perc. range & \multicolumn{2}{|c|}{$5-100$} & \multicolumn{2}{c|}{$10-100$} & \multicolumn{2}{c|}{$0-90$} & \multicolumn{2}{c|}{$0-95$} \\
\hline & $\delta$ & $\delta_{i}$ & $\delta$ & $\delta_{i}$ & $\delta$ & $\delta_{i}$ & $\delta$ & $\delta_{i}$ \\
\hline$\hat{\tau}$ & 21.5 & 19.5 & 21.5 & 19.5 & 24.0 & 22.5 & 22.5 & 21.5 \\
$S u p T$ & $10.76^{* * *}$ & $10.15^{* * *}$ & $12.44^{* * *}$ & $11.81^{* * *}$ & $7.87^{* * *}$ & $7.49^{* * *}$ & $8.45^{* * *}$ & $8.14^{* * *}$ \\
$\hat{\delta}$ & $-0.027^{*}$ & $-0.021^{* * *}$ & $-0.028^{*}$ & $-0.022^{* * *}$ & $-0.023^{*}$ & $-0.018^{*}$ & $-0.016^{*}$ & -0.011 \\
$\overline{\mathbf{b}}$ & $0.22^{*}$ & $0.26^{*}$ & $0.51^{*}$ & $0.49^{*}$ & $0.38^{* *}$ & $0.41^{* * *}$ & $0.36^{*}$ & $0.39^{*}$ \\
\hline $\mathrm{CD}$ & 0.00 & 0.00 & 0.00 & 0.00 & 0.00 & 0.02 & 0.00 & 0.00 \\
$R^{2}$ & 0.37 & 0.38 & 0.40 & 0.40 & 0.38 & 0.38 & 0.37 & 0.38 \\
$N \times T$ & 2978 & 2978 & 2816 & 2816 & 2617 & 2617 & 2849 & 2849 \\
\hline
\end{tabular}

Notes: Statistical significance denoted by $* 10 \%, * * 5 \%$, and ${ }^{* * *} 1 \%$. CD is the cross-section dependence test statistic of Pesaran (2004).

Figure 5: Benchmark estimates and sensitivity to institutional quality - GHG

$\tau$

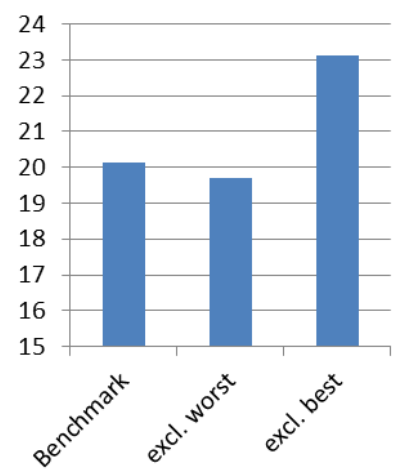

$\boldsymbol{\delta}$

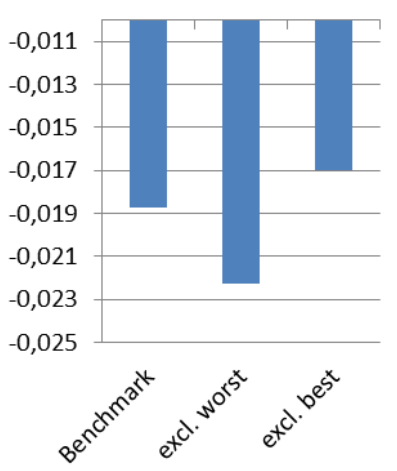

b

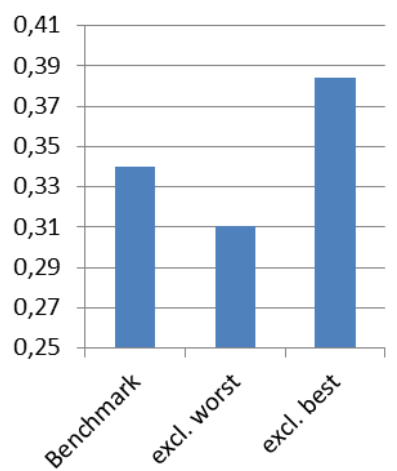

Note: Averages over CS-ARDL models. $\tau, \delta$ and b correspond to the threshold, the rate of change of emissions after the threshold and the long-term effect og GDP growth on emissions. Benchmark corresponds to the average of estimates reported in Table 3 Estimates for "excl. worst" and "excl. best" corresponds to the averages of CS-ARDL(2,2,2) models reported in Table 5 and $\operatorname{CS}-\operatorname{ARDL}(1,1,1)$ models whose results are available upon request.

\section{Concluding remarks}

This article provides some empirical evidence on the procyclicality of emissions of pollutants and investigates the role of institutional quality in the features of the relationship 
between pollution and economic growth. We adopt a non-linear empirical approach that borrows from the EKC literature while accounting for the various criticisms made to previous empirical work. More specifically, our approach is immune to issues related to the integration order of variables and accounts for endogeneity issues, bi-directional causality, heterogeneity across countries and cross-sectional dependence. Based on a large panel of countries at various stages of development, we show evidence of non-linearities between economic expansion and pollution. In the case of CO2 emissions, we find an inflexion point in the average growth of emissions for countries whose per capita income is greater than U.S.\$ 18,500. Although CO2 emission growth is lower for richer countries, it remains positive, unlike predicted by the standard EKC where pollution declines once per capita income is higher than the threshold income. In the case of GHG emissions, we however find evidence of an inverted U-curve with a turning point at U.S.\$20,000. Our results also confirm a significant degree of procyclicality of emissions. For one percentage point increase in real per capita GDP growth, the emissions of CO2 are higher by 0.5 percentage point (and GHG emissions are higher by 0.3 percentage point).

We then test for the role of institutional quality in the relationship between pollution and growth. Our empirical analysis shows that countries with better institutional quality experience inflexion or turning points at lower per capita income. Moreover, once such threshold development levels are passed, CO2 or GHG emission growth is much lower for countries with high-quality institutions. The procyclicality of emissions is also reduced for countries with the best institutional scores. By reducing the procyclicality of pollution, the improvement in institutional quality is therefore a key factor in attenuating the environmental externalities of economic growth. 


\section{References}

Annicchiarico, B. and Di Dio, F. (2015). Environmental policy and macroeconomic dynamics in a new Keynesian model. Journal of Environmental Economics and Management, 69(C):1-21.

Apergis, N. (2016). Environmental Kuznets curves: New evidence on both panel and country-level CO2 emissions. Energy Economics, 54(C):263-271.

Arrow, K., Bolin, B., Costanza, R., Dasgupta, P., Folke, C., Holling, C. S., Jansson, B.O., Levin, S., Maler, K.-G., Perrings, C., and Pimentel, D. (1995). Economic growth, carrying capacity, and the environment. Ecological Economics, 15(2):91-95.

Brock, W. A. and Taylor, M. S. (2003). The kindergarten rule of sustainable growth. NBER Working Papers 9597, National Bureau of Economic Research, Inc.

Chudik, A., Mohaddes, K., Pesaran, M. H., and Raissi, M. (2016). Long-run effects in large heterogeneous panel data models with cross-sectionally correlated errors. In Essays in Honor of Aman Ullah, volume 36 of Advances in Econometrics, pages 85135. Emerald Publishing Ltd.

Chudik, A., Mohaddes, K., Pesaran, M. H., and Raissi, M. (2017). Is there a debtthreshold effect on output growth? The Review of Economics and Statistics, 99(1):135150.

Chudik, A. and Pesaran, M. H. (2015). Common correlated effects estimation of heterogeneous dynamic panel data models with weakly exogenous regressors. Journal of Econometrics, 188(2):393-420.

Dasgupta, S. and De Cian, E. (2016). Institutions and the environment: Existing evidence and future directions. FEEM Working Paper 41.2016, Fondazione Eni Enrico Mattei.

Grossman, G. M. and Krueger, A. B. (1991). Environmental impacts of a North American Free Trade Agreement. NBER Working Papers 3914, National Bureau of Economic Research, Inc.

Haseeb, A., Xia, E., Danish, Baloch, M. A., and Abbas, K. (2018). Financial development, globalization, and CO2 emission in the presence of EKC: evidence from BRICS countries. Environmental Science and Pollution Research, 25. 
Heutel, G. (2012). How Should Environmental Policy Respond to Business Cycles? Optimal Policy under Persistent Productivity Shocks. Review of Economic Dynamics, 15(2):244-264.

Kaika, D. and Zervas, E. (2013a). The Environmental Kuznets Curve (EKC) theory Part A: Concept, causes and the CO2 emissions case. Energy Policy, 62(C):1392-1402.

Kaika, D. and Zervas, E. (2013b). The Environmental Kuznets Curve (EKC) theory Part B: Critical issues. Energy Policy, 62(C):1403-1411.

Lee, C. and Lee, J. (2009). Income and CO2 emissions: Evidence from panel unit root and cointegration tests. Energy Policy, 37(2):413-423.

Lieb, C. M. (2003). The Environmental Kuznets Curve A survey of the empirical evidence and of possible causes. Discussion Paper Series 391, University of Heidelberg.

Lopez, R. and Mitra, S. (2000). Corruption, pollution, and the kuznets environment curve. Journal of Environmental Economics and Management, 40(2):137-150.

Panayotou, T. (1993). Empirical tests and policy analysis of environmental degradation at different stages of economic development. Ilo working papers, International Labour Organization.

Panayotou, T. (2003). Economic growth and the environment. Technical report, Center for International Development at Harvard University, CID Working Papers.

Pesaran, M. (1997). The role of economic theory in modelling the long run. Economic Journal, 107(440):178-91.

Pesaran, M. and Smith, R. (1995). Estimating long-run relationships from dynamic heterogeneous panels. Journal of Econometrics, 68(1):79-113.

Pesaran, M. H. (2004). General diagnostic tests for cross section dependence in panels. Technical report.

Phillips, P. and Sul, D. (2003). Dynamic panel estimation and homogeneity testing under cross section dependence. Econometrics Journal, 6(1):217-259.

Selden, T. and Daqing, S. (1994). Environmental quality and development: Is there a kuznets curve for air pollution emissions? Journal of Environmental Economics and Management, 27(2):147-162. 
Shafik, N. and Bandyopadhyay, S. (1992). Economic growth and environmental quality: time series and cross-country evidence. Policy Research Working Paper Series 904, The World Bank.

Stern, D. I. (2004). The rise and fall of the environmental Kuznets curve. World Development, 32(8):1419-1439. 


\section{Appendix: Statistical sources}

Table 6: Data description and sources

\begin{tabular}{|c|c|c|}
\hline Variables & Description & Source \\
\hline $\begin{array}{c}\text { Pollution variables } \\
\text { CO2 emissions } \\
\text { GHG emissions }\end{array}$ & $\begin{array}{c}\text { CO2 emissions (metric tons per capita) } \\
\text { GHG emissions (kt CO2 equiv/pop) }\end{array}$ & $\begin{array}{c}\text { World Bank(EN.ATM.CO2E.PC) } \\
\text { World Bank(EN.ATM.GHGT) }\end{array}$ \\
\hline $\begin{array}{c}\text { Economic growth } \\
\text { GDP per capita }\end{array}$ & GDP per capita (constant 2010 U.S. \$) & World Bank(NY.GDP.PCAP.KD) \\
\hline $\begin{array}{c}\text { Institutional quality } \\
\text { Institutional score (main) } \\
\text { Institutional score (alt) }\end{array}$ & Quality of Institution: Regulatory \\
\hline $\begin{array}{c}\text { Quality of Institution: Rule of law } \\
\text { Control variables } \\
\text { Trade openness }\end{array}$ & $\begin{array}{c}\text { Worldwide Governance Indicators } \\
\text { Worldwide Governance Indicators }\end{array}$ \\
$\begin{array}{c}\text { Energy consumption } \\
\text { Share of manuf. ind. } \\
\text { Urbanisation }\end{array}$ & $\begin{array}{c}\text { Electric power cons. (kWh per capita) } \\
\text { Industry, value added (\% total) } \\
\text { Urban population (\% total) }\end{array}$ & $\begin{array}{c}\text { World Bank(EG.USE.ELEC.KH) } \\
\text { World Bank(NV.IND.MANF.ZS) } \\
\text { World Bank(SP.URB.TOTL.IN.ZS) }\end{array}$ \\
\hline
\end{tabular}

